This is a self-archived - parallel published version of this article in the publication archive of the University of Vaasa. It might differ from the original.

\title{
Internal audit function characteristics and external auditors' co-sourcing in different institutional contexts
}

Author(s): Jokipii, Annukka; Di Melo, Fabrizio

Title: Internal audit function characteristics and external auditors' cosourcing in different institutional contexts

Year: $\quad 2019$

Version: Accepted manuscript

Copyright (C)2019 Wiley. This is the pre-peer reviewed version of the following article: Jokipii, A. \& Di Melo, F. (2019). Internal audit function characteristics and external auditors' co-sourcing in different institutional contexts. International Journal of Auditing 23(2), 292307 , which has been published in final form at https://doi.org/10.1111/ijau.12162. This article may be used for noncommercial purposes in accordance with Wiley Terms and Conditions for Use of Self-Archived Versions.

\section{Please cite the original version:}

Jokipii, A. \& Di Melo, F. (2019). Internal audit function characteristics and external auditors' co-sourcing in different institutional contexts. International Journal of Auditing 23(2), 292-307. https://doi.org/10.1111/ijau.12162 


\title{
Internal audit function characteristics and external auditors' co-sourcing in different institutional contexts
}

\begin{abstract}
We examine the association between several characteristics of an internal audit function (IAF) and fees paid to external auditors to support internal audit activities (co-sourcing). We also analyze how this relation is influenced by the mandatory or voluntary implementation of IAFs. By using data from the Common Body of Knowledge (CBOK) study, which was conducted by the Institute of Internal Auditors Research Foundation (IIARF) in 2015, we find that more consultingoriented IAFs and more autonomous IAFs are likely to pay higher co-sourcing fees, while IAFs with greater expertise are likely to pay lower co-sourcing fees. While results related to consulting activities hold regardless of the institutional context, the negative association between IAF expertise and co-sourcing fees paid to support internal audit activities only holds in mandatory IAF environments, and the positive association between IAF autonomy and co-sourcing fees paid only holds where IAF is voluntary.
\end{abstract}

Keywords: Internal audit, Internal audit function, Co-sourcing, Fees, IAF focus, IAF expertise, IAF autonomy, Mandatory, Voluntary. 


\section{Introduction}

The shift that internal audit functions (IAFs) have experienced from assurance to consulting activities in many firms (Allegrini et al., 2011; Soh and Martinov-Bonnie, 2015) has increased the importance of internal audit in firms' organizations (Speklé et al., 2007), as more consulting-oriented IAFs are better able to enhance corporate governance through their relationships with the audit committee, the management and the external auditors (Gramling et al., 2004; Hazem and Roberts, 2018). To respond to the increasing importance of IAFs in firms' corporate governance, firms can choose to develop the required internal audit skills and abilities inside an organization, or to adopt the strategy of co-sourcing internal audit activities (Selim et al., 2009). In a typical co-sourcing arrangement, responsibilities for the IAF remain inside the organization. However, through co-sourcing, the IAF is likely to obtain, from the outside of the organization, special expertise and skills that may be difficult to achieve inside an organization due to limited resources available or limited employees' skills. The most common services that are likely to be co-sourced are typically reviews of internal control activities, or testing processes related to financial reporting, risk management, and regulatory compliance (Carey et al., 2006). Through co-sourcing, internal auditing can maximize internal audit activities without hiring new employees, or without substantially increasing the corresponding expenses (Dame, 2000). Accordingly, prior studies focusing on co-sourcing of internal auditing suggest that the primary reasons to co-source is to gain efficiency, to save costs (Abdolmohammadi, 2013), and to further increase flexibility and expertise when needed the most (Van Peursem and Jiang, 2008).

This study examines co-sourcing between internal audit of an organization and external audit firms. Previous empirical studies analyze variables that may lead firm's organization to use co-sourcing to develop their internal audit activities. For example, characteristics related to the size or the location of an organization (Widener and Selto, 1999; Abdolmohammadi, 2013), asset specificity and frequency (Speklé et al., 2007; Widener and Selto, 1999), ownership (Diaz-Mora and Triguero-Cano, 2012) and audit committee activities (Abbott et al., 2007; Abdolmohammadi, 2013) are expected to be considered by the management of a firm in deciding whether to use cosourcing for internal activities. Other studies (Ahlawat and Lowe, 2004; Gramling and Vandervelde, 2006) examine the results obtained through co-sourcing, rather than 
firms' characteristics that may lead to co-sourcing-related decisions. For example, Dickins and O'Reilly (2009) find a positive association between the percentage of cosourced internal audit work and the frequency of material weaknesses in internal control. They also find a negative relationship between the likelihood of the internal auditor reporting to the audit committee and the level of internal auditing co-sourcing. However, previous studies have analyzed the determinants of co-sourcing by using internal audit or firm characteristics that are observable from outside the firm, without considering characteristics such as the focus of an IAF (such as consulting vs. assurance activities), its expertise, or its autonomy from the management. Also, these previous studies do not take into account how the determinants of the co-sourcing decision may depend on whether the IAF is mandated by law and regulations. Although there may not be significant differences in the IAF characteristics for firms in countries with voluntary or mandatory IAF implementation, the effect of IAF characteristics over co-sourcing may differ in alternative institutional contexts. In a context where IAF is mandatory, co-sourcing may be mainly motivated by receiving assistance to achieve requirements from laws and regulations. On the contrary, in a context where IAF is voluntary, co-sourcing may be due to the need of strengthening corporate governance in a context of agency theory, where internal audit may serve as a monitoring response to agency costs (Carey et al., 2000).

In this study, we analyze how IAF characteristics that are observed inside an organization may have an influence on the co-sourcing decision. In particular, we consider (1) IAFs that are more focused on either consulting or assurance activities, (2) IAF expertise, which takes into account the expertise of internal audit employees acquired both outside and inside an organization, and (3) IAF autonomy, which measures to what extent internal audit activities are constrained by the management and by a limited number of sources to establish the audit plan (the lower the constrains, the higher the autonomy). We argue that, when the IAF is more focused on consulting activities, rather than on assurance activities, the IAF needs more specialized non-routine co-sourcing assistance. We also argue that IAF expertise decreases the need for co-sourcing, as more expert IAF employees are less likely to ask for external auditors' assistance in internal audit activities. Finally, we expect that more autonomous IAFs are likely to increase support from external auditors for their activities, as more autonomous IAFs are less subject to constrains from the management or from other specific areas of the organization. Therefore, more 
autonomous IAFs are likely to need further external assistance to comply with unregulated activities to serve both management and the audit committee (which IAFs normally refer to). Besides discussing the association between IAF characteristics and co-sourcing, we also analyze the effect that the mandatory or voluntary implementation of IAFs may have on the association between IAF characteristics and co-sourcing fees paid to support internal audit activities. Because, to our knowledge, this issue has been unexplored in previous literature, we adopt, in our hypotheses development, an exploratory approach, supposing that there are no differences in the associations between IAF characteristics and co-sourcing fees to support internal audit activities depending on different institutional contexts.

To test our hypotheses, we use the Common Body of Knowledge (CBOK) 2015 study conducted by the Institute of Internal Auditors Research Foundation (IIARF) in 2015. This database provides characteristics of internal audit that are evaluated inside an organization and, more specifically, by internal audit employees. Our sample includes 393 companies in 8 different geographic areas, and our results confirm our expectations. Specifically, we find a positive association between IAFs focusing more on consulting activities and co-sourcing, and between IAF autonomy and co-sourcing. Our results also indicate a negative association between the level of IAF expertise and co-sourcing. With regards to the role of mandatory or voluntary IAF, we find that IAFs focusing on consulting activities, rather than on assurance activities, are likely to increase co-sourcing to support internal audit activities, regardless of whether internal audit is mandatory or voluntary. IAF expertise is likely to decrease co-sourcing fees to support internal audit activities only in firms where IAF is mandatory. We interpret this result by observing that greater expertise of IAF employees can help internal audit comply with specific requirements of laws and regulations without the need for support from external audit co-sourcing. Finally, the positive association between IAF autonomy and co-sourcing fees to support internal audit activities only holds when internal audit is voluntary. This result can be explained by arguing that the voluntary implementation of an IAF allows internal audit employees to operate without legal requirements. In this context, more autonomous IAFs, which already comply with their tasks without pressures from managers or from limited sources to establish an audit plan, are likely to operate with more unregulated activities that are not defined by laws and regulations, thus further increasing the need for support from co-sourced external auditors. 
Our results contribute to prior research in several ways. First, to test our hypotheses, we use characteristics that are observed inside an organization, and not by using measures of internal audit, such as age of employees, internal audit certifications, or organizational characteristics, that are normally observable outside the firm. The characteristics we analyze are concerned with the audit plan and risk areas (IAF focus), with employees' education and certifications related to internal audit, IAF tenure, internal development of activities, and managerial rotation in the IAF (IAF expertise), and with the sources used to establish an internal audit audit plan and pressures to modify findings and reports of the internal department (IAF autonomy). To test our expectations, we also use a holistic approach, using measures of IAF focus, IAF expertise, and IAF autonomy that are composite measures of individual IAF characteristics. This approach, which is usual in corporate governance literature, allows us to decrease the noise that individual measures are likely to contain (Larcker et al., 2007). Second, we contribute to internal auditing and cosourcing literature by providing evidence that the association between IAF characteristics and co-sourcing fees to support internal audit activities is different in organizations having mandatory or voluntary IAFs, which may affect the interpretation of the results in previous studies. Finally, this study contributes to corporate governance literature by examining the characteristics of internal audit and co-sourcing fees across countries. The results potentially show the internal audit determinants of co-sourcing not just from one country, but from a broader international level.

The remainder of the paper is structured as follows: Section 2 develops the hypotheses. Section 3 describes our dataset, the research design, and the definition of our variables. Section 4 reports and discusses the results. Finally, Section 5 concludes.

\section{Hypotheses development}

In this section, we develop hypotheses about the effects that internal audit characteristics are likely to have on co-sourcing fees. Then, we analyze how these associations between internal audit characteristics and co-sourcing fees may change, depending on whether internal audit is mandatory or voluntary, according to laws and regulations of the geographic regions where firms are domiciled. 


\subsection{IAF characteristics and co-sourcing fees to support internal audit activities}

In recent years, internal auditing has evolved by providing more consulting than assurance activities (Allegrini et al., 2011), and internal audit practitioners expect internal audit to be even less focused on operational and compliance audits and audits of financial risks, and more focused on consulting activities such as corporate governance, enterprise risk management, strategic reviews, social and sustainability audits and ethics audits during the upcoming years (Allegrini et al., 2011; Soh and Martinov-Bennie, 2015). This internal audit's shift from assurance to consulting activities may accelerate the use of co-sourcing, because external firms providing assistance to internal audit are normally considered as able to provide the latest technological resources, industry specialization and experienced professionals to assist IAFs (Carey et al., 2006). However, Powell (1997) suggests that the high staff turnover and the employment of junior staff, which are recurrent in big firms providing external services, might compromise internal audit quality (Carey et al., 2006). Also, external providers do not have specific information about customers as firms demanding for co-sourcing might have, thus further decreasing the efficiency of co-sourced internal control (Barr and Chang, 1993).

We hypothesize that, when internal audit is more concentrated on consulting activities, rather than on assurance activities, it will be more likely to pay higher cosourcing fees to external auditors to support internal audit activities. Our expectation is in line with Widener and Selto (1999), who find that the co-sourcing of non-routine internal audit activities is more costly than the co-sourcing of routine tasks. Thus, our hypothesis is as follows:

H1: IAFs with a greater focus on consulting activities are associated with higher co-sourcing fees to support internal audit activities.

Another characteristic of the IAF that is likely to lead to co-sourcing decisions of internal audit activities is represented by the expertise of IAF employees. We take into account the professional expertise of the internal audit employees that they obtained both outside the firm, through their education and through the internal audit certifications they obtained, and inside the organization, through the number 
of years IAF has been taken place within a firm (IAF tenure), the management training ground, and the ability of IAFs to develop their activities internally.

The professional expertise internal audit employees can obtain through their education and through certifications related to internal audit is likely to have an effect on the quality of internal control. In fact, higher financial expertise is likely to reduce the incidence of internal control problems (Krishan, 2005) and the disclosure of material weaknesses (Lin et al., 2011). Because financial expertise has a positive impact on the quality of internal controls, we may expect higher external financial expertise to reduce the need for IAFs to co-source their activities, as the employees already have the skills to efficiently run their activities.

The expertise of internal audit employees can be increased also internally. With regards to the tenure of an IAF, Carey et al. (2006) find that most of the companies that decided to outsource internal audit activities did not have an in-house internal department before that decision. Also, Mohammed et al. (2012) find that an increasing IAF tenure leads to more mature and competent IAFs. This result might be interpreted as more experienced IAFs not needing as much support as unexperienced IAFs.

While it may be argued that greater IAF tenure increases IAF experience and, thus, decreases the need for co-sourcing IAF activities, it can be observed that firms reporting an internal audit department may also decide to co-source part of IAF activities, especially in larger organizations where the complexity of internal audit is higher (Carey et al., 2006). To increase the IAF experience on how to deal with complex situations, practices such as the management training ground that are common in countries such as US may be implemented. The management training ground can be defined as "a company targeting internal auditors for hire into management positions outside of the IAF" (Messier et al., 2011, page 2132). Although internal auditors are viewed by external auditors as less objective when an IAF is used as a management training because internal auditors are likely to bias their work to meet managers' expectations (Messier et al., 2011), internal auditors may also be perceived as competent, as managers have the opportunity to better evaluate internal auditors' ability (Brown, 1983; Galloway, 1995; Gramling et al., 2004). Also, through the management training ground, internal auditors are expected to increase their interaction with the management of the organization. According to this alternative view of management training ground increasing 
internal auditors' competence, co-sourcing may be considered as a loss of opportunity to implement the training program and, thus, to increase internal auditors' knowledge about the whole organization (Barr and Chang, 1993; Adams, 1994). Following the stream of literature arguing that the management training ground would increase IAF's knowledge about an organization, we expect it to improve internal auditors' experience inside an organization.

Finally, IAF experience inside an organization is also likely to be determined by the ability of internal audit to develop its activities internally. External auditors' perception of an IAF is expected to change depending on whether internal audit activities are developed externally or internally (Abbott at el., 2012), as the more internal audit activities are developed internally, the higher the IAF experience. By developing internal audit activities internally, internal auditors are able to acquire knowledge about risk management and internal control, and to strengthen appropriate inter-personal and behavioral skills inside an organization (Sarens et al., 2009).

By taking into account all the previous considerations about IAF expertise developed both outside and inside an organization, we expect that IAF expertise is likely to decrease co-sourcing fees to support internal audit activities. We thus formulate the second hypothesis as follows:

H2: IAFs with greater expertise are associated with lower co-sourcing fees to support internal audit activities.

Another IAF characteristic that is likely to have an influence on fees paid to support internal audit activities is IAF autonomy. To remain autonomous, IAF would seek to avoid any actions that violate their independence. The importance of IAF autonomy to preserve its independence is also demanded by the Institute of Internal Auditors (IIA), which requires internal auditors to be objective and independent in performing their activities (IIA 2015). To be objective, an IAF needs to be less influenced by managers or specific tasks determined by limited sources to establish an audit plan, so that the IAF is more likely to find and report internal control problems to the audit committee (Lin et al., 2011). Therefore, to better perform their activities, internal auditors must remain unbiased (Norman et al., 2010).

An IAF is more likely to remain autonomous when the IAF uses several sources when establishing an audit plan. Because IAFs can be generally involved in a wide 
range of activities not necessarily or exclusively related to financial reporting, such as operational and system audits, or internal consulting related to firm's projects (Prawitt et al., 2009), we expect that a broader range of IAF activities, represented by several sources used in establishing the audit plan, is more likely to require greater external support through co-sourcing.

IAF autonomy is also likely to increase when internal auditors are able to report their findings in internal audit reports without pressures from the management. Also, internal control deficiencies are more likely to be detected when internal audit reports directly to the audit committee rather than to management (Bedard and Graham, 2011).

IAFs that are more effective in finding material weaknesses, as internal audit employees are not pressured or influenced by the management when reporting the findings, and can use multiple sources to establish the audit plan, may ask for cosourcing to support internal audit activities. The co-sourcing of some internal audit activities may further increase the chance of detecting material weaknesses, especially in those environments where managers' pressure is lower. Thus, we expect that more autonomous IAFs may require greater support from co-sourcing activities, which in turns is translated into higher fees. We formulate, then, our third hypothesis as follows:

H3: IAFs with greater levels of autonomy are associated with higher cosourcing fees to support internal audit activities.

\subsection{IAF characteristics and co-sourcing fees to support internal audit activities in} different institutional contexts

Although we expect focus, expertise, and autonomy of IAFs to have an influence on the level of co-sourcing for internal audit activities, the associations we defined in our hypotheses may suffer changes depending on whether the IAF is voluntary or mandatory for specific organizations in a given institutional context. While there is a wide range of empirical literature about the substitution or complementary effect between internal and external audit activities (Elliot and Korpi, 1978; Stein et al., 1994; Carey et al., 2000; Felix et al., 2001; Hay et al., 2006; Hay et al., 2008; Ho and Hutchinson, 2010; Prawitt et al., 2011; Mohamed et al., 2012), there are no studies, to 
our knowledge, examining the relationship between IAF characteristics and cosourcing, depending on whether the IAF is voluntary or mandatory.

The IAF implementation in specific organizations can be voluntary or mandatory, depending on the institutional context of countries where firms are domiciled. In countries where IAF is mandatory, IAF implementation is likely to be motivated by applying legal requirements. However, often the implementation of an IAF is required only for listed companies. Also, the details of IAF implementation are often not determined by laws or regulations. For example, in the New York Stock Exchange, where IAF is mandatory, laws and regulations do not require specific professional qualifications, or do not define the scopes of the IAF (Chambers and Odar, 2015). Finally, some countries apply restrictions to co-sourcing internal audit activities. For example, co-sourcing of internal audit to incumbent external auditors is forbidden in US under SOX 2002, because it may result in significant economic bonding (Abbott et al., 2007). Therefore, such services are provided in US by non-incumbent external audit firms or by non-audit firms specialized in services related to internal audit activities.

In environments where internal audit is voluntary, firms' response to pressure for monitoring is often explained through agency theory. According to this theory, IAF is considered as a cost borne by managers (agents) to satisfy owners' (principals') demands to increase firms' accountability and, therefore, to reduce information asymmetries (Sherer and Kent, 1983; Sarens and Abdolmohammadi, 2011). For example, Wallace and Kreutzfeld (1991) find that firms with implemented IAFs have more skilled management and accounting personnel, and larger, more competitive, more profitable and more conservative accounting policies, compared to firms without IAF in US. However, Carey et al. (2000) study external and internal auditing in Australian family firms and find that variables related to the agency theory do not explain the existence of IAF in voluntary environments. Al-Twaijry et al. (2003) find that Saudi companies do not voluntarily implement IAF motivated by the reliance on external auditors or by the cost-benefit trade-off. Finally, Goodwin-Steward and Kent (2006) find that, in Australian companies, there is a strong association between voluntary internal audit and the size of the firm. However, they do not find any relation between voluntary IAF and the complexity of business structures, while they obtain mixed results for the voluntary use of internal audit as a way to strengthen corporate governance mechanisms. 
Although previous literature analyzing internal audit across countries on a macro level observes that the variability in professional qualifications may partially be explained by cultural differences (Sarens and Abdolmohammadi, 2010) and by the degree of the economic development of a country (Abdolhommadi and Tucker, 2002), the association between IAF characteristics and external auditing to support internal audit activities depending on whether IAF is voluntary or mandatory has not been explored yet. Although we believe that this association is likely to change according to different institutional contexts, the lack of a related theoretical background leads us to formulate the corresponding hypotheses supposing no differences between mandatory and voluntary IAFs. Therefore, our fourth hypotheses are as follows:

H4a: The positive association between IAF focusing on consulting activities and co-sourcing fees to support internal audit activities is expected to hold in both mandatory and voluntary IAFs.

H4b: The negative association between IAF expertise and co-sourcing fees to support internal audit activities is expected to hold in both mandatory and voluntary IAFs.

H4c: The positive association between IAF autonomy and co-sourcing fees to support internal audit activities is expected to hold in both mandatory and voluntary IAFs.

\section{Data, methods, and variable definitions}

\subsection{Data}

This study is based on data provided by the Institute of Internal Auditors (IIA) from the series of surveys known as the Common Body of Knowledge (CBOK). The CBOK 2015 survey, which was the third global initiative of its kind, was offered to the members of IIA world widely in 23 languages. The data provided included 14,517 respondents from 166 countries. The respondents work in organizations in different industries and firm sizes with a differing range of activities. To test our hypotheses, we require that all the firms in our sample have an IAF and paid fees to external auditors to support internal audit activities, because firms not having an IAF or not 
declaring whether they paid fees to external auditors cannot show evidence about the hypotheses analyzed in this study. In the dataset, the variable with the smallest number of observations is co-sourcing fees paid to external auditors to support internal audit activities, as this variable is available in 839 observations. Because we require all the observations to have available data for all the variables we include in the model, and after winsorizing variables at $1 \%$ and $99 \%$ as it is common to avoid the effect of outliers, we finally obtain 393 observations (174 related to voluntary internal audit, and 219 related to mandatory internal audit) from eight different geographic areas (Africa, Asia, Pacific, Europe, Middle East, North America, South and Central America, and the Caribbean). Table 1 reports the number of firms in our sample for each country, classified according to the geographic area.

\subsection{Research design}

To test the associations between co-sourcing fees paid to external auditors to support internal audit activities and IAF characteristics, we use the following model:

$$
\begin{aligned}
& \text { Co-sourcingFees }(\ln )_{i t} \\
& \qquad \begin{aligned}
= & \alpha+\beta_{1} \text { IAFfocus }_{i t}+\beta_{2} \text { IAFexpertis }_{i t}+\beta_{3} \text { IAFautonomy }_{i t} \\
& +\sum \beta_{j} \text { Controls }_{j, i t}+\varepsilon_{i t}
\end{aligned}
\end{aligned}
$$

We run Equation (1) by using the ordinary least-square (OLS) estimation. To control for the effects that geographical regions of firms' incorporation are likely to have on co-sourcing fees, we include region dummies among the control variables.

The dependent variable, Co-sourcingFees(ln), is fees paid by an organization to cosource internal audit activities with the external auditors. The CBOK (2015) question used is "What were last year's approximate fees paid to external auditors to support or perform internal audit work?", and the variable used in our tests is the natural logarithm of co-sourcing fees paid to external auditors to support internal audit activities.

The three independent variables of interest are IAFfocus, IAFexpertise, and IAFautonomy. These three variables are composite measures of IAF characteristics. In 
particular, IAFfocus includes the percentage of the audit plan that has been made taking into account several categories of risks (Audit plan), and the kind of responsibilities IAF has inside the organizations (Risk areas). IAFexpertise indicates external expertise, which includes education and an internal audit certification, and internal expertise, which incorporates the years IAF has been taken place in firms' organization (Tenure), the ability of IAF to develop its activities internally (Internal), and managerial rotation in the IAF (Rotation). Finally, IAFautonomy is measured through the number of sources that are used to establish an audit plan (Source), and through the pressure IAF has suffered to change or suppress a valid internal audit report or finding (Modify). We run Equation (1) by using both the composite measures, and their individual components.

Controls indicates the control variables, that include existence and characteristics of audit committees, the mandatory requirement for organizations of the existence of an internal audit department, the number of employees, the natural logarithm of total assets, and the natural logarithm of sales. Also, due to heavy legal requirements, firms in regulated industries may be more subject to perform their internal audit activities in-house rather than to co-source them to external service providers. For this reason, we also control for dummy variables representing different industries the firms in our sample belong to.

Finally, to analyze whether the mandatory incorporation of an IAF has an effect on the association between IAF characteristics and co-sourcing fees paid to support internal audit activities, we run Equation (1) separately for two portfolios of observations, depending on whether IAF is mandatory or voluntary for a specific organization, according to laws and regulations of firms' region of domiciliation.

\subsection{Variable definitions}

To analyze the effects that IAF characteristics are likely to have on co-sourcing fees paid to support internal audit activities, we take into account three IAF composite measures: IAF focus, IAF expertise, and IAF autonomy. As it is usual in the corporate governance literature (Larcker et al., 2007), the use of variables that include different dimensions of internal audit is expected to decrease the noise that individual proxies might contain if used alone. Next, we describe the three IAF composite measures, along with the individual proxies used to compute them. The description of the IAF composite measures is also summarized in Table 2. 
IAF focus measures whether the internal audit department is more focused on assurance or consulting activities. The two proxies that are included in our variable of IAF focus are audit plan and risk areas. Audit plan reflects the percentage of 2015 audit plan that has been made up of several categories of risk. Our proxy is a dummy variable that takes the value of 1 if the sum of the audit plan percentages related to strategic business risks, risk management assurance/effectiveness, information technology not covered in other audits, third-party relationships, crisis management, and general financing, which can all be considered as consulting activities, is greater than (or equal to) 50 percent, and 0 otherwise. The variable Risk areas identifies the responsibilities related to risk that internal audit has in the organization. The dichotomous variable takes the value of 1 if, according to the respondents of the survey, the IAF provides advice and consulting on risk management activities, and 0 if employees believe that internal audit provides assurance on individual risks and on risk management as a whole. The variable IAF focus is the sum of the two dichotomous variables listed above. Thus, IAF focus is a discrete variable that can take a value from 0 to 2 . The higher the value, the more the IAF is focused on consulting activities.

$I A F$ expertise is measured by considering both the level of expertise employees may have acquired outside the organization, and the expertise accumulated inside the organization. For external expertise, we take into account employees' Education and Certification. Education is a dummy variable that takes the value of 1 if the employee holds a Master or a Doctorate degree, and 0 otherwise. Certification takes the value of 1 if employees hold a certification related to IA, and 0 otherwise. The variable $I A F$ external expertise is the sum of the two variables above. Also, we measure internal expertise through a composite measure of the following three variables: Tenure, Internal, and Rotation. With regard to IAF tenure, we expect that the higher the number of years IAF has taken place inside an organization, the higher the IAF expertise referred to that organization. The related dichotomous variable takes the value of 1 if the number of years is greater than (or equal to) the median of the years, computed by geographic region, and 0 otherwise. The variable Internal analyzes the ability of the IAF to develop its activities internally. In particular, the variable takes the value of 1 if internal audit activities are provided inside the organization, and 0 otherwise. Finally, organizations favoring managers' rotation inside the IAF is likely to increase its expertise. Thus, the related dichotomous variable (Rotation) takes the 
value of 1 if the organization has a process to rotate, formally or informally, managers into the IAF, and 0 otherwise. The variable IAF internal expertise is the sum of the three dichotomous variables listed above. Thus, our composite measure can take a discrete value from 0 to 3 . In our tests, we also use the variable IAF expertise, which is the sum of external and internal expertise.

For IAF autonomy, which measures the absence of constrains to the IAFs from the management and from other specific areas of the organization in complying with their tasks, we take into account the variables Source and Modify. Source measures the number of sources that are used to establish an audit plan. There are ten different sources listed in the survey, such as previous year's audit plan, compliance or regulatory requirements, organizations' strategies and objectives, consultation with external auditors business heads, or requests from management, audit committee, or external auditors. It can be argued that the higher the number of sources that are used, the more autonomous is the IAF. Because the median of this variable is 5, our variable Source takes the value of 1 if the number of sources is greater than 5 , and 0 otherwise. The variable Modify considers whether the IAF experienced a situation in which employees were directed to suppress, or significantly modify, a valid internal audit finding or report. The corresponding variable (Modify) takes the value of 1 if respondent never experienced such a pressure, and 0 otherwise. The variable $I A F$ autonomy is the sum of the two dummy variables above and, thus, can take a value from 0 to 2 .

In Equation (1), we use control variables that are likely to have an influence on the co-sourcing fees paid to external auditors to support internal audit activities. To take into account the importance of audit committee characteristics on IAFs (Goodwin, 2003; Krishnan, 2005; Zain et al., 2006; Abdulaziz, 2015), we also construct a composite measure that takes into account three dimensions of firms' audit committees. First, we consider the existence of an audit committee in an organization. The corresponding dichotomous variable takes the value of 1 if there is an audit committee or equivalent in the organization, and 0 otherwise. Second, we consider the number of meetings that the audit committee approximately had in the last fiscal year. The related dummy variable takes the value of 1 if the number of meetings of the audit committee is greater than the median, computed by industry and region, and 0 otherwise. Finally, we take into account whether the chief audit executive (CAE) or 
director were invited to an audit committee meeting. The corresponding dummy variable takes the value of 1 if the number of meetings CAE or director were invited to is higher than the median, computed by industry and region, and 0 otherwise. Our composite measure for audit committee is the sum of the three dichotomous variables above and, thus, can take a discreet value from 0 (no audit committee in an organization) to 3. Mandatory is a dummy variable that takes the value of 1 if the internal audit department is mandatory for an organization according to laws and regulations, and 0 otherwise. To take into account IAF size, we include in the model the number of fulltime equivalent employees in the internal audit department. Finally, we control for firm size through the natural logarithm of total assets and the natural logarithm of sales, and for geographical areas and industry by including the related dummy variables.

\section{Results}

\subsection{Descriptive statistics}

Table 3 shows the descriptive statistics. Audit plan has a mean equal to 0.3664 , and a median equal to 0 . The number of observations reporting a value of Audit plan equal to 1 is 144 , corresponding to the $36.64 \%$ of the sample. This suggests that, in most of the firms in our sample, the audit plan has been made up mainly taking into account the assurance activities. However, when we consider the responsibilities that internal audit members have in internal audit, the $57,51 \%$ of our sample (corresponding to 226 observations) reports a value of Risk areas equal to 1, indicating that, in most of the firms, IAF provides consulting on risk management activities. While most of the respondents (59.03\% of the sample, which corresponds to 232 observations) hold a Master or a Doctorate degree, as indicated by the mean of the variable Education, $56.49 \%$ of the employees in the survey have a certificate related to IA. With regard to IAF tenure, 167 observations (42.49\% of the sample) reports a value equal to 1 and correspond to firms having IAF for a number of years greater than the median, computed by geographic region. The descriptive statistics related to the variables Internal and Rotation also indicate that most of the firms have low levels of internal expertise (the means of the two variables are 0.3359 and 0.2188 , respectively). In fact, 132 observations (33.59\% of the sample) develop their activities internally, and only

86 observations $(21.88 \%$ of the sample) experience an organization favoring 
managers' rotation inside the IAF. Most of the firms have autonomous IAF characteristics. 225 observations (57.25\% of the sample) report a value of Source equal to 1, suggesting that most of the firms use a high number of sources to establish their audit plan, and 351 observations (89.31\% of the sample) report a value of Modify equal to 1 , indicating that most of the firms never experienced pressures to modify or suppress a valid internal audit finding or report. The median of Audit committee is equal to 3, indicating that most of the firms (83.21\% of the sample) report an existing audit committee in their organization. Finally, descriptive statistics about the variable Mandatory report a mean equal to 0.5573 and a median equal to 1 , indicating that most of the companies in our sample have compulsory implementation of an IAF, according to laws and regulations of the country they are domiciled in.

Table 4 reports the correlation matrix. The negative and significant correlation between Co-sourcing fees (ln) and Internal indicates that co-sourcing fees paid to support internal audit activities are reduced when internal audit activities are developed internally, while the positive correlation between Co-sourcing fees (ln) and Source suggests that fees paid to support internal audit activities tend to increase when the number of sources to establish the internal audit plan increases. This positive correlation may be due to higher complexity of internal audit when the number of sources increases, which is likely to lead to higher co-sourcing fees to support internal audit. The negative and significant correlation between Risk areas and Modify suggests that responsibilities in advice and consulting activities are lower when organizations are less pressured to modify a valid internal audit finding or report. The negative and significant correlation between Certification and Internal may suggest a negative effect between the ability of IAF employees to develop internal audit activities internally and the requirement of an internal audit certification that firms may demand to their employees. Also, the negative and significant correlation between Certification and Modify indicates that those employees with higher external expertise are those that experienced less pressure in suppressing and/or modifying a valid internal audit finding or report. The positive and significant correlation between Tenure and Mandatory indicates that IAFs are taken place for a higher number of years when internal audit is mandatory by country laws or regulations. The negative and significant correlation between Internal and Source suggests that an IAF develops its activities internally when there are less different sources used to establish an internal audit plan. Finally, the positive correlation 
between Audit committee and Co-sourcing fees indicates that stronger audit committee characteristics require higher co-sourcing fees, while the positive correlation between Audit committee and Mandatory suggests that audit committees are likely to be stronger when IAF is mandatory.

We also run correlations using the composite measures of IAF characteristics, instead of the individual items. Untabulated coefficients show that there is no significant correlation between co-sourcing fees and any of the composite measures, except for IAF autonomy, which reports a positive and significant correlation, supporting Hypothesis 3. There is also a negative and significant correlation between external and internal expertise, and a positive and significant correlation between IAFs that are more consulting-oriented and IAF expertise, which include both external and internal expertise, suggesting that IAFs that are more oriented towards consulting activities are also those that require a higher level of expertise of its employees.

Finally, the high correlation between the natural logarithms of total assets and sales (0.6596) may imply a multicollinearity problem in our empirical model. To address this concern, we compute the variance inflation factors (VIFs) of both of the variables, which are equal to 2.37 for Total assets (ln), and 2.35 for Sales (ln). These values indicate a low magnitude of multicollinearity. To further exclude any multicollinearity issue, we also run Equation (1) by excluding either Total assets (ln) or Sales $(\ln )$ from the list of independent variables, and the main results remain stable.

\subsection{The determinants of co-sourcing fees paid to support internal audit activities}

Table 5 analyzes the determinants of co-sourcing fees. After including all the variables in the model, the number of observations is 393. Column (1) reports results when the components of IAF focus, IAF expertise, and IAF autonomy are included separately in the model, while Column (2) refers to results when IAF focus, IAF expertise (differentiated into external and internal expertise), and IAF autonomy are included as composite measures. In both columns, Mandatory, Audit committee, the size of IAFs (number of employees) and the size of firms (in terms of sales) report a positive and significant association with co-sourcing fees paid to assist internal audit.

With regard to the individual components of IAF focus, Table 5, Column (1), shows that the more the audit plan is dedicated to consulting activities (variable: Audit plan), the higher the co-sourcing fees firms are likely to pay to support internal audit 
activities (coef. 0.3277, p-value 0.031). Risk areas, on the contrary, does not report a significant association with co-sourcing fees at conventional levels. Education and Certification, which are individual components of external expertise, have no significant associations with co-sourcing fees, while Tenure, which is a component of IAF internal expertise, report a negative and significant coefficient (coef. -0.2641, pvalue 0.089). The variable Rotation, which is also a component of IAF external expertise, is not related to co-sourcing fees at conventional levels. Finally, between the two dimensions of IAF autonomy (Source and Modify), only the variable Source reports a positive and significant coefficient (coef. 0.2943, p-value 0.042).

When we include in the model the composite measures of IAF characteristics (Table 5, Column (2)), IAF focus reports a positive and significant association with the dependent variable (coef. 0.2781, p-value 0.014), supporting the idea that, when the IAF is more oriented towards consulting activities, organizations are willing to pay higher co-sourcing fees to support internal audit activities. The composite measure of IAF external expertise is negative, but not significant at conventional levels. The higher expertise employees may have earned outside the firm through higher education levels of internal audit certifications does not significantly reduce co-sourcing fees. This unexpected result may be explained by arguing that, although employees with higher educational and auditing background may require less external support to develop their activities, they may also better understand the issues related to internal audit and, thus, they may want internal audit activities to be further improved, also by increasing the activities provided through co-sourcing. The composite measure related to internal expertise, however, reports a negative and significant association with co-sourcing fees (coef. -0.1804, p-value 0.072). This significant association suggests that employees that achieved higher levels of expertise inside an organization are also those that are more likely to rely less on external assistance. We also run Equation (1) by using only one proxy of expertise, which is the sum of internal and external expertise, and the corresponding (untabulated) coefficient is negative and significant (coef. -0.2284, p-value 0.064). This is consistent with our expectations of more expert IAFs needing less assistance from external auditors (Hypothesis H2). Finally, more autonomous IAFs are likely to increase co-sourcing fees to support internal audit activities, as indicated by the positive and significant coefficient of the composite measure related to IAF autonomy (coef. 0.2216, p-value 0.078). This result supports Hypothesis 3 regarding the 
expected positive association between more autonomous IAFs and fees paid to assist the IAF.

In Table 6, we report results by creating two portfolios of observations: one with firms with mandatory implementation of an IAF for an organization, and one with firms with voluntary implementation of an IAF. Columns (1) and (2) report results when IAF is not mandatory and mandatory, respectively, and include the individual components of IAF focus, expertise, and autonomy, separately. Columns (3) and (4) report results when IAF is not mandatory and mandatory, respectively, using the composite measures of IAF focus, expertise, and autonomy.

Results with individual IAF components and with observations of firms with voluntary implementation of an IAF (Table 6, Column (1)) indicate that Audit plan has a positive and significant association with co-sourcing fees (coef. 0.4076, p-value 0.092), Tenure is negatively and significantly associated with fees paid to support internal audit activities (coef. -0.4616, p-value 0.073), and Source reports a positive and significant coefficient (coef. 0.6053, p-value 0.023). When IAF is mandatory (Table 6, Column (2)), among the individual IAF characteristics, only Risk areas reports a positive and significant coefficient, while the other IAF characteristics are not significant at conventional levels.

With regards to the composite measures of IAF characteristics (Table 6, Columns (3) and (4)), results suggest that the more the IAF is focused on consulting activities, the higher the fees paid to support internal audit activities, regardless of whether IAF is mandatory or not. IAF external expertise does not significantly affect co-sourcing fees, regardless of whether the IAF is voluntary or mandatory. However, IAF internal expertise is likely to decrease co-sourcing fees only when IAF is mandatory (coef. 0.2619, p-value 0.040), while the association between IAF expertise and co-sourcing fees paid is not significant at conventional levels when IAF is voluntary (Table 5, Column (3)). The result is similar when we run the same model using IAF expertise that incorporates both external and internal expertise, with an untabulated coefficient of -0.1806 , and with a p-value of 0.060 when IAF is mandatory, and with a coefficient that is no longer significant when the IAF is voluntary. Finally, IAF autonomy increases co-sourcing fees paid to support internal audit activities only when IAF is not mandatory (coef. 0.4941, p-value 0.017), while the same association is no longer significant in firms domiciled with mandatory IAF implementation. These results indicate that the voluntary or mandatory implementation of the IAF affects the 
associations between co-sourcing fees paid to support internal audit activities and both IAF expertise and IAF autonomy. IAF expertise and, especially, internal expertise, is likely to decrease co-sourcing fees only when IAF is mandatory, while IAF autonomy increases co-sourcing fees only when IAF is voluntary.

\subsection{Discussion of the results}

This study examines the relationship between fees paid by organizations in cosourcing internal audit activities and characteristics of the IAF, and how this relationship can change in a mandatory or voluntary context of IAF implementation.

Results confirm our expectations regarding the relationship between IAF characteristics and fees paid to support internal audit activities. We find a positive association between IAF consulting activities and co-sourcing fees, which is in line with the shift from assurance to consulting IAF activities (Allegrini et al., 2011; Soh and Martinov-Bennie, 2015) being likely to accelerate the use of co-sourcing. Firms reporting consulting-oriented IAFs should, then, tend to increase internal audit employees' expertise if they want to avoid recurring to co-sourcing. In this way, internal audit employees would develop skills and abilities that would allow IAFs to permanently cope with the complex consulting tasks of an IAF. IAF autonomy has also a positive association with co-sourcing fees, as more autonomous IAFs are expected to comply with a wider range of activities without constrains from management or from a limited number of sources to establish the audit plan. The greater level of unregulated activities, which already characterizes internal auditing (Prawitt et al., 2009), is likely to increase the need for external support. Although greater autonomy of IAFs reduces the constrains for IAFs in their activities, it also implies a need for wider skills and abilities, due to the increase of different types of activities. To be efficient, more autonomous IAFs should, then, either increase cosourcing or, alternatively, increase employees' expertise. Results also indicate a negative association between IAF expertise and, in particular, IAF internal expertise, and co-sourcing fees, which is in line with more experienced IAFs being more competent (Mohammed et al., 2012) and, thus, needing less external support.

By analyzing the data in voluntary and mandatory IAF contexts, we find that, regardless of the institutional context, IAFs focusing on consulting activities pay higher co-sourcing fees to support internal audit activities. IAF expertise decreases the co-sourcing fees paid to external auditors only in firms domiciled in regions where 
IAF is mandatory, especially if expertise has been developed inside an organization. This is probably due to more expert IAFs needing less external audit collaboration to implement specific laws' and regulations' requirements. Thus, in institutional environments where the implementation of IAFs is regulated, firms may improve internal audit employees' expertise to permanently comply with laws and regulations, rather than pay co-sourcing fees to comply with those legal requirements. Finally, the positive association between IAF autonomy and co-sourcing fees only holds in geographic regions where internal audit is voluntary, which indicates that the voluntary implementation of IAFs further increases the positive association between IAF autonomy and co-sourcing. In fact, more autonomous IAFs, which are those that comply with their tasks without pressures from managers or from limited sources to establish an audit plan, may also operate without legal requirements. Thus, the voluntary IAF implementation further increases the range of their unregulated activities and, thus, the need for co-sourcing.

Our results related to the voluntary or mandatory implementation of an IAF have implications regarding how external auditors can support internal audit activities. Cosourcing is generally able to support IAFs when IAFs have a greater focus on consulting (rather than assurance) activities. However, in regions where IAF is mandatory, it may be less expensive for firms to invest resources in increasing internal audit employees' expertise to comply with specific requirements from law and regulations, rather than paying co-sourcing fees in an environment that, due to laws and regulations, is likely to be more standardized. On the contrary, in regions where IAFs are voluntary, it may be convenient for firms to pay co-sourcing fees to external auditors to support a less standardized volume of tasks, being therefore subject to a greater number and complexity of tasks. Thus, we do not suggest that cosourcing is always (or never) convenient to firms. Rather, we believe that co-sourcing may be useful depending on the characteristics of each IAF, and on the institutional environment of each organization.

\section{Conclusions}

In this paper, we study the associations between IAF characteristics and cosourcing, and how these associations can vary in different institutional contexts. We find that more consulting-oriented and more autonomous IAFs are likely to increase co-sourcing, while IAFs with more expertise decrease co-sourcing fees paid to 
external auditors. We also find that more consulting-oriented IAFs are likely to pay more co-sourcing fees regardless of the institutional context. However, IAF expertise decreases co-sourcing fees only when IAFs are mandatory, while IAFs autonomy increases co-sourcing fees only when IAFs are voluntary. The findings have implications for firms in optimizing their IAF.

As in all studies, also this one has its limitations that should be considered when interpreting our results. The variables used in the analysis are based on the responses of the CBOK 2015 survey participants, who were all internal auditors and members of the IIA. This may raise the possibility of a sampling bias. The respondents were anonymous and we were not able to check the given answers. Also, the availability of further accounting, financial, and corporate governance variables was limited to the ones offered in the survey. Although we attempted to match the CBOK dataset with other databases, such as Datastream, to increase the number of accounting and economic variables we may have used in our empirical models as control variables, the number of observations that matched in the two databases was very limited. Finally, the questions included in the survey were administrated by the IIARF, which had a strong influence on the definition of the variables we used in our research.

Further research may analyze the association between IAF characteristics and cosourcing fees in specific countries where external legal shocks, such as changes in the IAF's requirements, or in the mandatory or voluntary implementation of IAFs in specific countries, may increase the heterogeneity of the sample that in our study is given by considering several geographic areas. Also, researchers may explore the optimal balance between IAF characteristics and co-sourcing fees paid to support internal audit activities to minimize managerial opportunistic behaviors in the most efficient way. According to our findings, this balance is likely to change depending on different institutional contexts and may imply policy implications for regulators in a given country to improve the interaction between internal audit and co-sourcing. 


\section{References}

Abbott, L.J., Parker, S., \& Peters, G.F. (2012). Audit fee reductions from internal audit provided assistance: the incremental impact of internal audit characteristics. Contemporary Accounting Research, 29, 94-118.

Abbott, L.J., Parker, S., Peters, G.F., \& Rama, D.V. (2007). Corporate governance, audit quality, and the Sarbanes-Oxley Act: evidence from internal audit outsourcing. The Accounting Review, 82, 803-835.

Abdolmohammadi, M. (2013). Correlates of co-sourcing/outsourcing of internal audit activities. Auditing: A Journal of Practice \& Theory, 32, 69-85.

Abdolmohammadi, M., \& Tucker, R. (2002). The influence of accounting and auditing on a country's economic development. Review of Accounting and Finance, 1, $42-53$.

Abdulaziz, A. (2015). Influence of audit committees on internal audit conformance with internal audit standards. Managerial Auditing Journal, 30, 539-559.

Adams, M.B. (1994). Agency theory and the internal audit. Managerial Auditing Journal, 9, 8-12.

Ahlawat, S.S., \& Lowe, D.J. (2004). An examination of internal auditor objectivity: in-house vs. outsourcing. Auditing: A Journal of Practice \& Theory, 23, 147-158.

Al-Twaijry, A. A. M., Brierley, J. A., \& Gwilliam, D. R. (2003). The development of Internal Audit in Saudi Arabia: an Institutional theory perspective. Critical Perspectives on Accounting, 14, 507-531.

Allegrini, M., D’Onza, G., Melville, R., Sarens, G., \& Selim, G.M. (2011). What's Next for Internal Auditing? The IIA'S Global Internal Audit Survey: A Component of the CBOK Study. The Institute of Internal Auditors Research Foundation, Altamonte Springs, FL.

Barr, R., \& Chang, S. (1993). Outsourcing internal audits: a boon or bane? Managerial Auditing Journal, 8, 14-17.

Bedard, J.C., \& Graham, L. (2011). Detection and severity classifications of Sarbanes-Oxley Section 404 internal control deficiencies. The Accounting Review, 86, 825-855. 
Brown, P.R. (1983). Independent auditor judgment in the evaluation of internal audit functions. Journal of Accounting Research, 21, 444-455.

Carey, P., Simnett, R., \& G. Tanewski (2000). Voluntary demand for internal and external auditing by family businesses. Auditing: A Journal of Practice \& Theory: Supplement, 19, 37-51.

Carey, P., Subramaniam, N., \& Wee Ching, K.C. (2006). Internal audit outsourcing in Australia. Accounting and Finance, 46, 11-30.

Chambers, D., \& Odar, M. (2015). A new vision for internal audit. Managerial Auditing Journal, 30, 34-55.

Dame, D. (2000). Strategic use of recovery audit services and co-sourcing. Internal Auditing, 15, 44-45.

Díaz-Mora, C., \& Triguero-Cano, A. (2012). Why do some firms contract out production? Evidence from firm-level panel data. Applied Economics, 44, 1631-1644. Dickins, D., \& O'Reilly, D. (2009). The qualifications and independence of internal auditors. Internal Auditing, 24, 14-21.

Elliott, R.K., \& Korpi, A.R. (1978). Factors affecting audit fees. In Cost-benefit analysis of auditing, ed. M.F. Shakun. New York: AICPA.

Felix, W., Gramling, A., \& Maletta, M. (2001). The contribution of internal audit as a determinant of external audit fees and factors influencing this contribution. Journal of Accounting Research, 39, 513-534.

Galloway, D. (1995). Internal Auditing: A Guide for the New Auditor. Altamonte Springs, FL: The Institute of Internal Auditors.

Goodwin, J. (2003). The relationship between the audit committee and the internal audit function: Evidence from Australia and New Zealand. International Journal of Auditing, 7, 263-278.

Goodwin-Stewart, J., \& Kent, P. (2006). The use of internal audit by Australian companies. Managerial Auditing Journal, 21, 81-101.

Gramling, A.A., Maletta, M.J., Schneider, A., \& Church, B.K. (2004). The role of the internal audit function in corporate governance: a synthesis of the extant internal 
auditing literature and directions for future research. Journal of Accounting Literature, 23, 194-244.

Gramling, A.A, \& Vandervelde, S.D. (2006). Assessing internal audit quality. Internal Auditing, 21, 26-33.

Hay, D., Knechel, R., \& Wong, N. (2006). Audit Fees: A meta analysis of the effect of supply and demand attributes. Contemporary Accounting Research, 23, 141-191. Hay, D., Knechel, R., \& Ling, H. (2008). Evidence on the impact of internal control and corporate governance on audit fees. International Journal of Auditing, 12, 9-24. Hazem, R.I., \& Roberts, C. (2018). Factors affecting the voluntary use of internal audit: evidence from the UK. Managerial Auditing Journal, 33, 288-317.

Ho, S. \& Hutchinson, M. (2010). Internal audit department characteristics/activities and audit fees: some evidence from Hong Kong firms. Journal of International Accounting, Auditing and Taxation, 19, 121-136.

Krishnan, J., (2005). Audit committee quality and internal control: An empirical analysis. The Accounting Review, 80, 649-675.

Larcker, D.F., Richardson, S.A., \& Tuna, I. (2007). Corporate governance, accounting outcomes, and organizational performance. The Accounting Review, 82, 963-1008.

Lin, S., Pizzini, M., Vargus, M., \& Bardhan, I.R. (2011). The role of the internal audit function in the disclosure of material weaknesses. The Accounting Review, 86, 287323.

Messier, W. Jr., Reynolds, K., Simon, C., \& Wood, D. (2011). The effect of using the internal audit function as a management training ground on the external auditor's reliance decision. The Accounting Review, 86, 2131-2154.

Mohamed, Z., Zain, M., Subramaniam, N., \& Yusoff, W. (2012). Internal audit attributes and external audit's reliance on internal audit: implications for audit fees. International Journal of Auditing, 16, 268-285.

Norman, C., Rose, A., \& Rose, J. (2010). Internal audit reporting lines, fraud risk decomposition and assessment of fraud risk. Accounting, Organization and Society, $35,546-557$.

Powell, S. (1997). Inside co-sourcing. Management Accounting - London 75, 52. 
Prawitt, D.F., Sharp, N., \& Wood, D. (2011). Reconciling archival and experimental research: does internal audit contribution affect the external audit fee? Behavioral Research in Accounting, 23, 187-206.

Prawitt, D.F., Smith, J.L., \& Wood, D. (2009). Internal audit quality and earnings management. The Accounting Review, 84, 1255-1280.

Sarens, G., \& Abdolmohammadi, M. (2010). Cultural dimension effects on professionalism of internal auditing practice in various countries. working paper.

Sarens, G., \& Abdolmohammadi, M. (2011). Monitoring effect of the internal audit function: Agency theory versus other explanatory variables. International Journal of Accounting, 15, 1-20.

Sarens, G., De Beelde, I., \& Everaert, P. (2009). Internal audit: a comfort provider to the audit committee. The British Accounting Review, 41, 90-106.

Selim, G., Woodward, S., \& Allegrini, M. (2009). Internal auditing and consulting practice: a comparison between UK/Ireland and Italy. International Journal of Auditing 13, 9-25.

Sherer, M. \& Kent, D. (1983). Auditing and Accountability. London: Pitman.

Soh, D., \& Martinov-Bennie, N. (2015). Internal auditors' perceptions of their role in environmental, social and governance assurance and consulting. Managerial Auditing Journal, 30, 80-111.

Soh, D., \& Martinov-Bennie, N. (2016). Factors associated with internal audit's involvment in environmental and social assurance and consulting. International Journal of Auditing, 22, 404-421.

Speklé, R.F., van Elten, H.J., \& Kruis, A.M. (2007). Sourcing of internal auditing: an empirical study. Management Accounting Research, 18, 102-124.

Stein, M., Simunic, D., \& O'Keefe, T. (1994). Industry differences in the production of audit services. Auditing, 13, 128-143.

Van Peursem, K., \& Jiang, L. (2008). Internal audit co-sourcing practice and rationales: SMEevidence from New Zealand. Asian Review of Accounting, 16, 219245. 
Wallace, W., \& Kreutzfeldt, R. (1991). Distinctive characteristics of entities with an internal audit department and the association of the quality of such departments with errors. Contemporary Accounting Research, 7, 485-512.

Widener, S., \& Selto, F. (1999). Management control systems and boundaries of the firm: why do firms co-source internal audit activities? Journal of Management Accounting Research, 11, 45-73.

Zain, M.M., Subramaniam, N., \& Stewart, J. (2006). Internal auditors' assessment of their contribution to financial statement audits: The relation with audit committee and internal audit function characteristics. International Journal of Auditing, 10, 1-18. 
Table 1 - Countries and sample firms

\begin{tabular}{|c|c|c|c|}
\hline \multicolumn{4}{|c|}{ Africa: 28 firms } \\
\hline Botswana & 1 & South Africa & 8 \\
\hline Cote d'Ivoire (Ivory Coast) & 2 & Swaziland & 1 \\
\hline Ghana & 1 & Tanzania, United Republic of & 2 \\
\hline Madagascar & 1 & Uganda & 1 \\
\hline Mauritius & 2 & Zimbabwe & 7 \\
\hline Nigeria & 2 & & \\
\hline \multicolumn{4}{|c|}{ Asia: 60 firms } \\
\hline Armenia & 1 & Malaysia & 4 \\
\hline Bangladesh & 1 & Pakistan & 4 \\
\hline China & 21 & Phillippines & 1 \\
\hline India & 5 & Singapore & 1 \\
\hline Indonesia & 3 & Taiwan & 6 \\
\hline Japan & 13 & & \\
\hline \multicolumn{4}{|c|}{ Pacific: 11 firms } \\
\hline Australia & 10 & Papua New Guinea & 1 \\
\hline \multicolumn{4}{|c|}{ Europe: 108 firms } \\
\hline Austria & 2 & Macedonia & 1 \\
\hline Belgium & 1 & Montenegro & 1 \\
\hline Croatia & 1 & Norway & 1 \\
\hline Cyprus & 1 & Poland & 3 \\
\hline Czech Republic & 3 & Portugal & 3 \\
\hline Denmark & 5 & Romania & 2 \\
\hline Estonia & 1 & Russia & 1 \\
\hline France & 10 & Serbia & 2 \\
\hline Germany & 15 & Slovenia & 1 \\
\hline Greece & 4 & Spain & 10 \\
\hline Hungary & 1 & Sweden & 2 \\
\hline Iceland & 1 & Switzerland & 22 \\
\hline Italy & 4 & Turkey & 5 \\
\hline Latvia & 1 & Ukraine & 1 \\
\hline Luxembourg & 2 & United Kingdom & 1 \\
\hline \multicolumn{4}{|c|}{ Middle East: 27 firms } \\
\hline Israel & 7 & Qatar & 1 \\
\hline Kuwait & 1 & Saudi Arabia & 9 \\
\hline Lebanon & 1 & United Arab Emirates & 7 \\
\hline Oman & 1 & & \\
\hline \multicolumn{4}{|c|}{ North America: 95 firms } \\
\hline Canada & 14 & United States & 81 \\
\hline \multicolumn{4}{|c|}{ South and Central America: 55 firms } \\
\hline Argentina & 5 & Honduras & 1 \\
\hline Bolivia & 1 & Mexico & 1 \\
\hline Brazil & 7 & Nicaragua & 3 \\
\hline Chile & 8 & Panama & 2 \\
\hline Colombia & 6 & Paraguay & 1 \\
\hline Costa Rica & 6 & Peru & 1 \\
\hline Ecuador & 8 & Uruguay & 1 \\
\hline El Salvador & 4 & & \\
\hline \multicolumn{4}{|c|}{ The Caribbean: 9 firms } \\
\hline Bahamas & 1 & Cayman Islands & 2 \\
\hline Barbados & 1 & Dominican Republic & 2 \\
\hline $\begin{array}{l}\text { Bonaire, Saint Eustatius } \\
\text { and Saba }\end{array}$ & 1 & Puerto Rico & 2 \\
\hline Total: & 393 & & \\
\hline
\end{tabular}


Table 2 - Definition of the IAF composite measures

\begin{tabular}{|c|c|}
\hline IAF focus & $\begin{array}{l}\text { Discrete variable, computed as the sum of Audit plan and Risk areas. It } \\
\text { can take a value from } 0 \text { to } 2 \text {. }\end{array}$ \\
\hline Audit plan & $\begin{array}{l}\text { Dichotomous variable that takes the value of } 1 \text { if the percentage of } \\
\text { consulting-related activities in the } 2015 \text { audit plan is greater than (or } \\
\text { equal to) } 50 \text { percent, and } 0 \text { otherwise. }\end{array}$ \\
\hline Risk areas & $\begin{array}{l}\text { Dichotomous variable that takes the value of } 1 \text { if employees believe } \\
\text { that the IAF provides advice and consulting on risk management } \\
\text { activities, and } 0 \text { otherwise. }\end{array}$ \\
\hline $\begin{array}{l}\text { IAF external } \\
\text { expertise }\end{array}$ & $\begin{array}{l}\text { Discrete variable, computed as the sum of Education and Certification. } \\
\text { It can take a value from } 0 \text { to } 2 \text {. }\end{array}$ \\
\hline Education & $\begin{array}{l}\text { Dichotomous variable that takes the value of } 1 \text { if the employee holds a } \\
\text { Master or a Doctorate degree, and } 0 \text { otherwise. }\end{array}$ \\
\hline Certification & $\begin{array}{l}\text { Dichotomous variable that takes the value of } 1 \text { if the employee has a } \\
\text { professional qualification in internal audit, and } 0 \text { otherwise. }\end{array}$ \\
\hline $\begin{array}{l}\text { IAF internal } \\
\text { expertise }\end{array}$ & $\begin{array}{l}\text { Discrete variable, computed as the sum of Tenure, Internal, and } \\
\text { Rotation. It can take a value from } 0 \text { to } 3 \text {. }\end{array}$ \\
\hline Tenure & $\begin{array}{l}\text { Dichotomous variable that takes the value of } 1 \text { if the number of years } \\
\text { internal audit has taken place into an organization is greater than (or } \\
\text { equal to) the median of the years, computed by geographic region, and } \\
0 \text { otherwise. }\end{array}$ \\
\hline Internal & $\begin{array}{l}\text { Dichotomous variable that takes the value of } 1 \text { if internal audit } \\
\text { activities are developed inside the organization, and } 0 \text { otherwise. }\end{array}$ \\
\hline Rotation & $\begin{array}{l}\text { Dichotomous variable that takes the value of } 1 \text { if managers rotate into } \\
\text { the IAF, and } 0 \text { otherwise. }\end{array}$ \\
\hline IAF autonomy & $\begin{array}{l}\text { Discrete variable, computed as the sum of Source and Modify. It can } \\
\text { take a value from } 0 \text { to } 2 .\end{array}$ \\
\hline Source & $\begin{array}{l}\text { Dichotomous variable that takes the value of } 1 \text { if the number of sources } \\
\text { used to establish an audit plan is greater than } 5 \text { out of } 10 \text { listed sources, } \\
\text { and } 0 \text { otherwise. }\end{array}$ \\
\hline Modify & $\begin{array}{l}\text { Dichotomous variable that takes the value of } 1 \text { if respondents never } \\
\text { experienced pressures to suppress or significantly modify a valid } \\
\text { internal audit finding or report, and } 0 \text { otherwise. }\end{array}$ \\
\hline
\end{tabular}


Table 3 - Descriptive statistics

\begin{tabular}{|c|c|c|c|c|c|}
\hline Variables & $25^{\text {th }}$ percentile & Mean & Median & $75^{\text {th }}$ percentile & $\begin{array}{r}\text { Standard } \\
\text { deviation }\end{array}$ \\
\hline $\begin{array}{r}\text { Co-sourcing fees } \\
(\ln )\end{array}$ & 10.3090 & 11.3994 & 11.5129 & 12.5426 & 1.6766 \\
\hline Audit plan & 0 & 0.3664 & 0 & 1 & 0.4824 \\
\hline Risk areas & 0 & 0.5751 & 1 & 1 & 0.4950 \\
\hline Education & 0 & 0.5903 & 1 & 1 & 0.4924 \\
\hline Certification & 0 & 0.5649 & 1 & 1 & 0.4964 \\
\hline Tenure & 0 & 0.4249 & 0 & 1 & 0.4950 \\
\hline Internal & 0 & 0.3359 & 0 & 1 & 0.4729 \\
\hline Rotation & 0 & 0.2188 & 0 & 0 & 0.4140 \\
\hline Source & 0 & 0.5725 & 1 & 1 & 0.4953 \\
\hline Modify & 1 & 0.8931 & 1 & 1 & 0.3093 \\
\hline Mandatory & 0 & 0.5573 & 1 & 1 & 0.4973 \\
\hline Audit committee & 1 & 1.9924 & 3 & 3 & 1.1834 \\
\hline $\begin{array}{l}\text { Number of } \\
\text { employees }\end{array}$ & 2 & 6.9786 & 5 & 9 & 6.7170 \\
\hline Total assets $(\ln )$ & 18.2929 & 19.9424 & 20.5608 & 21.8219 & 3.0138 \\
\hline Sales $(\ln )$ & 17.3120 & 19.0844 & 19.5193 & 21.1287 & 2.8493 \\
\hline
\end{tabular}

The number of observations is 393. Co-sourcing fees $(\mathrm{ln})$ is the natural logarithm of co-sourcing fees paid to support IA. Audit plan is a dichotomous variable that takes the value of 1 if the percentage of consulting-related activities in the 2015 audit plan is greater than (or equal to) 50 percent, and 0 otherwise. Risk areas is a dichotomous variable that takes the value of 1 if employees believe that internal audit provides advice consulting on risk management activities, and 0 otherwise. Education is a dummy variable that takes the value of 1 if the employee holds a Master or a Doctorate degree, and 0 otherwise. Certification is a dichotomous variable that takes the value of 1 if the employee has a professional qualification or certification in internal audit, and 0 otherwise. Tenure is a dichotomous variable that takes the value of 1 if the number of years internal audit has taken place is greater than (or equal to) the median of the years, computed by geographic region, and 0 otherwise. Internal is a dichotomous variable that takes the value of 1 if internal audit activities are developed inside the organization, and 0 otherwise. Rotation is a dichotomous variable that takes the value of 1 if IAF employees rotate though other parts of the organization, and 0 otherwise. Source is a dichotomous variable that takes the value of 1 if the number of sources used to establish an audit plan is greater than 5, and 0 otherwise. Modify is a dichotomous variable that takes the value of 1 if respondents never experienced a pressure to suppress or significantly modify a valid internal audit finding or report, and 0 otherwise. Mandatory is a dichotomous variable that takes the value of 1 if an internal audit department is mandated by law in an organization, and 0 otherwise. Audit committee is a composite measure for 
audit committee existence and characteristics. Total assets $(\mathrm{ln})$ is the natural logarithm of total assets. Sales $(l n)$ is the natural logarithm of sales. 
Table 4 - Correlation matrix

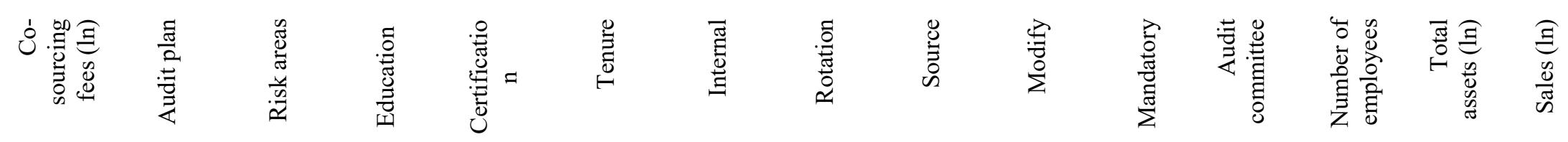

\begin{tabular}{|c|c|c|c|c|c|c|c|c|c|c|c|c|c|c|c|}
\hline $\begin{array}{r}\text { Co-sourcing } \\
\text { fees }(\ln )\end{array}$ & 1 & & & & & & & & & & & & & & \\
\hline Audit plan & 0.0445 & 1 & & & & & & & & & & & & & \\
\hline Risk areas & 0.0595 & -0.0193 & 1 & & & & & & & & & & & & \\
\hline Education & -0.0729 & 0.0644 & -0.0043 & 1 & & & & & & & & & & & \\
\hline Certification & 0.0751 & 0.0070 & 0.0554 & -0.0527 & 1 & & & & & & & & & & \\
\hline Tenure & 0.0515 & -0.0875 & 0.0517 & -0.0480 & 0.0588 & 1 & & & & & & & & & \\
\hline Internal & -0.1546 & 0.0406 & 0.0664 & -0.0430 & -0.1474 & -0.0337 & 1 & & & & & & & & \\
\hline Rotation & 0.0656 & 0.0573 & 0.0815 & -0.0221 & -0.0196 & 0.0057 & 0.0015 & 1 & & & & & & & \\
\hline Source & 0.2737 & 0.0700 & 0.1208 & -0.0295 & 0.1650 & 0.0873 & -0.1151 & 0.0344 & 1 & & & & & & \\
\hline Modify & 0.0149 & -0.0959 & -0.0974 & 0.0300 & -0.0876 & 0.0474 & -0.0330 & -0.0759 & -0.0658 & 1 & & & & & \\
\hline Mandatory & 0.0737 & 0.0080 & -0.0408 & 0.0075 & -0.0280 & 0.1030 & -0.0603 & 0.0009 & -0.0143 & -0.0430 & 1 & & & & \\
\hline $\begin{array}{r}\text { Audit } \\
\text { committee }\end{array}$ & 0.3033 & 0.0094 & 0.0162 & 0.0034 & 0.1593 & -0.0032 & -0.1367 & 0.0399 & 0.1859 & -0.0231 & 0.1286 & 1 & & & \\
\hline $\begin{array}{l}\text { Number of } \\
\text { employees }\end{array}$ & 0.3132 & -0.0170 & 0.0070 & -0.0422 & 0.0775 & 0.3473 & -0.0505 & 0.1253 & 0.1979 & 0.0836 & 0.1119 & 0.1940 & 1 & & \\
\hline $\begin{array}{r}\text { Total assets } \\
(\ln )\end{array}$ & 0.4121 & 0.0210 & -0.0579 & -0.0660 & 0.1365 & 0.1557 & -0.1080 & -0.0597 & 0.2022 & 0.0009 & 0.0219 & 0.2037 & 0.3609 & 1 & \\
\hline Sales (ln) & 0.4462 & -0.0159 & 0.0104 & -0.0357 & 0.0565 & 0.1094 & -0.0867 & 0.0578 & 0.2286 & 0.0228 & -0.0455 & 0.1248 & 0.3214 & 0.6596 & 1 \\
\hline
\end{tabular}


Pairwise Spearman correlations. Correlations in bold are significant at the $10 \%$ level.

The number of observations is 393. Co-sourcing fees $(\mathrm{ln})$ is the natural logarithm of co-sourcing fees paid to support IA. Audit plan is a dichotomous variable that takes the value of 1 if the percentage of consulting-related activities in the 2015 audit plan is greater than (or equal to) 50 percent, and 0 otherwise. Risk areas is a dichotomous variable that takes the value of 1 if employees believe that IAF provides advice consulting on risk management activities, and 0 otherwise. Education is a dummy variable that takes the value of 1 if the employee holds a Master or a Doctorate degree, and 0 otherwise. Certification is a dichotomous variable that takes the value of 1 if the employee has a professional qualification or certification in internal audit, and 0 otherwise. Tenure is a dichotomous variable that takes the value of 1 if the number of years internal audit has taken place is greater than (or equal to) the median of the years, computed by geographic region, and 0 otherwise. Internal is a dichotomous variable that takes the value of 1 if internal audit activities are developed inside the organization, and 0 otherwise. Rotation is a dichotomous variable that takes the value of 1 if IAF employees rotate though other parts of the organization, and 0 otherwise. Source is a dichotomous variable that takes the value of 1 if the number of sources used to establish an audit plan is greater than 5, and 0 otherwise. Modify is a dichotomous variable that takes the value of 1 if respondents never experienced a pressure to suppress or significantly modify a valid internal audit finding or report, and 0 otherwise. Mandatory is a dichotomous variable that takes the value of 1 if an internal audit department is mandated by law in an organization, and 0 otherwise. Audit committee is a composite measure for audit committee existence and characteristics. Total assets (ln) is the natural logarithm of total assets. Sales $(l n)$ is the natural logarithm of sales. 
Table 5 - The association between IAF characteristics and co-sourcing fees to support internal audit activities

\begin{tabular}{|c|c|c|}
\hline VARIABLES & Co-sourcing fees $(\ln )_{t}$ & Co-sourcing fees $(\ln )$ \\
\hline & Column (1) & Column (2) \\
\hline Intercept & $\begin{array}{r}7.7488 * * * \\
(0.000)\end{array}$ & $\begin{array}{r}5.9016^{* * * *} \\
(0.000)\end{array}$ \\
\hline Audit plan $_{\mathrm{t}}$ & $\begin{array}{r}0.3277 * * \\
(0.031)\end{array}$ & \\
\hline 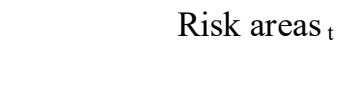 & $\begin{array}{c}0.1747 \\
(0.258)\end{array}$ & \\
\hline IAF focus $_{t}$ & & $\begin{array}{r}0.2781 * * \\
(0.014)\end{array}$ \\
\hline Education $_{\mathrm{t}}$ & $\begin{array}{r}-0.1146 \\
(0.422)\end{array}$ & \\
\hline Certification $_{\mathrm{t}}$ & $\begin{array}{r}-0.0891 \\
(0.558)\end{array}$ & \\
\hline Tenure $_{\mathrm{t}}$ & $\begin{array}{r}-0.2641^{*} \\
(0.089)\end{array}$ & \\
\hline Internal $_{\mathrm{t}}$ & $\begin{array}{r}-0.2340 \\
(0.148)\end{array}$ & \\
\hline Rotation $_{\mathrm{t}}$ & $\begin{array}{c}0.0292 \\
(0.886)\end{array}$ & \\
\hline IAF external expertise $_{t}$ & & $\begin{array}{r}-0.0930 \\
(0.371)\end{array}$ \\
\hline IAF internal expertise $_{t}$ & & $\begin{array}{r}-0.1804 * \\
(0.072)\end{array}$ \\
\hline Source $_{t}$ & $\begin{array}{r}0.2943 * * \\
(0.042)\end{array}$ & \\
\hline Modify $_{t}$ & $\begin{array}{c}0.0803 \\
(0.730)\end{array}$ & \\
\hline IAF autonomy $t$ & & $\begin{array}{r}0.2216^{*} \\
(0.078)\end{array}$ \\
\hline Mandatory $t$ & $\begin{array}{r}0.3736^{* *} \\
(0.014)\end{array}$ & $\begin{array}{r}0.3792 * * \\
(0.011)\end{array}$ \\
\hline Audit committee $_{t}$ & $\begin{array}{r}0.2081 * * * \\
(0.002)\end{array}$ & $\begin{array}{r}0.2213 * * * \\
(0.001)\end{array}$ \\
\hline Number of employees $_{t}$ & $\begin{array}{r}0.0459 * * * \\
(0.001)\end{array}$ & $\begin{array}{r}0.0460 * * * \\
(0.001)\end{array}$ \\
\hline Total assets $(\ln )_{\mathrm{t}}$ & 0.0663 & 0.0636 \\
\hline
\end{tabular}




\begin{tabular}{rrr} 
Region dummies & YES & YES \\
Industry dummies & YES & YES \\
Observations & 393 & 393 \\
$R^{2}$ & 0.407 & 0.402 \\
\hline
\end{tabular}

The values in brackets report p-value significance levels.

$*, * *, * * *$ indicate significance at $10 \%, 5 \%$, and $1 \%$ levels, respectively.

Co-sourcing fees $(\mathrm{ln})$ is the natural logarithm of co-sourcing fees paid to support IA. Audit plan is a dichotomous variable that takes the value of 1 if the percentage of consulting-related activities in the 2015 audit plan is greater than (or equal to) 50 percent, and 0 otherwise. Risk areas is a dichotomous variable that takes the value of 1 if employees believe that IAF provides advice consulting on risk management activities, and 0 otherwise. IAF focus is the sum of Audit plan and Risk areas. Education is a dummy variable that takes the value of 1 if the employee holds a Master or a Doctorate degree, and 0 otherwise. Certification is a dichotomous variable that takes the value of 1 if the employee has a professional qualification or certification in internal audit, and 0 otherwise. Tenure is a dichotomous variable that takes the value of 1 if the number of years internal audit has taken place is greater than (or equal to) the median of the years, computed by geographic region, and 0 otherwise. Internal is a dichotomous variable that takes the value of 1 if internal audit activities are developed inside the organization, and 0 otherwise. Rotation is a dichotomous variable that takes the value of 1 if IAF employees rotate though other parts of the organization, and 0 otherwise. IAF expertise is divided into external and internal expertise. External expertise is the sum of Education and Certification, while internal expertise is the sum of Tenure, Internal, and Rotation. Source is a dichotomous variable that takes the value of 1 if the number of sources used to establish an audit plan is greater than 5 , and 0 otherwise. Modify is a dichotomous variable that takes the value of 1 if respondents never experienced a pressure to suppress or significantly modify a valid internal audit finding or report, and 0 otherwise. IAF autonomy is the sum of Source and Modify. Mandatory is a dichotomous variable that takes the value of 1 if an internal audit department is mandated by law in an organization, and 0 otherwise. Audit committee is a composite measure for audit committee existence and characteristics. Number of employees is the number of IAF employees. Total assets (ln) is the natural logarithm of total assets. Sales $(l n)$ is the natural logarithm of sales. 
Table 6 - The association between IAF characteristics and co-sourcing fees to support internal audit activities in different contexts of corporate law

\begin{tabular}{|c|c|c|c|c|}
\hline VARIABLES & $\begin{array}{r}\text { Co-sourcing } \\
\text { fees }(\ln )_{\mathrm{t}}\end{array}$ & $\begin{array}{r}\text { Co-sourcing } \\
\text { fees }(\ln )_{\mathrm{t}}\end{array}$ & $\begin{array}{r}\text { Co-sourcing } \\
\text { fees }(\ln )_{\mathrm{t}}\end{array}$ & $\begin{array}{r}\text { Co-sourcing } \\
\text { fees }(\ln )_{\mathrm{t}}\end{array}$ \\
\hline & Column (1) & Column (2) & Column (3) & Column (4) \\
\hline & Mandatory $_{\mathrm{t}}=0$ & Mandatory $_{\mathrm{t}}=1$ & Mandatory $_{\mathrm{t}}=0$ & Mandatory $_{\mathrm{t}}=1$ \\
\hline Intercept & $\begin{array}{r}4.8861 * * * \\
(0.002)\end{array}$ & $\begin{array}{r}8.7547 * * * \\
(0.000)\end{array}$ & $\begin{array}{r}4.8047 * * * \\
(0.002)\end{array}$ & $\begin{array}{r}8.5610^{* * *} \\
(0.000)\end{array}$ \\
\hline Audit plan $_{t}$ & $\begin{array}{r}0.4076^{*} \\
(0.092)\end{array}$ & $\begin{array}{l}0.3348 \\
(0.106)\end{array}$ & & \\
\hline Risk areas t & $\begin{array}{l}0.1145 \\
(0.676)\end{array}$ & $\begin{array}{r}0.3702 * \\
(0.081)\end{array}$ & & \\
\hline IAF focus $_{t}$ & & & $\begin{array}{r}0.3316^{*} \\
(0.090)\end{array}$ & $\begin{array}{r}0.3588 * * \\
(0.021)\end{array}$ \\
\hline Education $_{\mathrm{t}}$ & $\begin{array}{l}-0.1206 \\
(0.591)\end{array}$ & $\begin{array}{r}-0.0058 \\
(0.978)\end{array}$ & & \\
\hline Certification $_{\mathrm{t}}$ & $\begin{array}{l}0.1482 \\
(0.588)\end{array}$ & $\begin{array}{l}-0.1519 \\
(0.456)\end{array}$ & & \\
\hline Tenure $_{\mathrm{t}}$ & $\begin{array}{r}-0.4616^{*} \\
(0.073)\end{array}$ & $\begin{array}{l}-0.1391 \\
(0.494)\end{array}$ & & \\
\hline Internal $_{t}$ & $\begin{array}{l}0.0069 \\
(0.974)\end{array}$ & $\begin{array}{r}-0.3369 \\
(0.153)\end{array}$ & & \\
\hline Rotation $_{t}$ & $\begin{array}{l}0.3684 \\
(0.266)\end{array}$ & $\begin{array}{r}-0.3500 \\
(0.204)\end{array}$ & & \\
\hline IAF external expertise ${ }_{t}$ & & & $\begin{array}{l}0.0138 \\
(0.935)\end{array}$ & $\begin{array}{r}-0.0749 \\
(0.599)\end{array}$ \\
\hline IAF internal expertise $_{t}$ & & & $\begin{array}{r}-0.0709 \\
(0.623)\end{array}$ & $\begin{array}{r}-0.2619 * * \\
(0.040)\end{array}$ \\
\hline Source $_{t}$ & $\begin{array}{r}0.6053^{* *} \\
(0.023)\end{array}$ & $\begin{array}{l}0.1613 \\
(0.398)\end{array}$ & & \\
\hline Modify $t$ & $\begin{array}{l}0.5046 \\
(0.138)\end{array}$ & $\begin{array}{r}-0.0502 \\
(0.872)\end{array}$ & & \\
\hline IAF autonomy $t$ & & & $\begin{array}{r}0.4941 * * \\
(0.017)\end{array}$ & $\begin{array}{l}0.1052 \\
(0.514)\end{array}$ \\
\hline Audit committee ${ }_{t}$ & $\begin{array}{r}0.2542^{* * * *} \\
(0.009)\end{array}$ & $\begin{array}{r}0.2037 * * \\
(0.028)\end{array}$ & $\begin{array}{r}0.2760 * * * \\
(0.005)\end{array}$ & $\begin{array}{r}0.1971 * * \\
(0.032)\end{array}$ \\
\hline Number of employees $t$ & $\begin{array}{l}0.0227 \\
(0.485)\end{array}$ & $\begin{array}{r}0.0743 * * * \\
(0.000)\end{array}$ & $\begin{array}{l}0.0122 \\
(0.668)\end{array}$ & $\begin{array}{r}0.0743 * * * \\
(0.000)\end{array}$ \\
\hline Total assets $(\ln )_{\mathrm{t}}$ & $\begin{array}{r}0.1180^{*} \\
(0.081)\end{array}$ & $\begin{array}{r}-0.0010 \\
(0.984)\end{array}$ & $\begin{array}{r}0.1190 * \\
(0.065)\end{array}$ & $\begin{array}{l}0.0031 \\
(0.947)\end{array}$ \\
\hline Sales $(\ln )_{\mathrm{t}}$ & $0.1160 *$ & $0.1131 * *$ & $0.1269^{* *}$ & $0.1176^{* *}$ \\
\hline
\end{tabular}




\begin{tabular}{rrrrr} 
Region dummies & YES & YES & YES & YES \\
Industry dummies & YES & YES & YES & YES \\
Observations & 174 & 219 & 174 & 219 \\
$R^{2}$ & 0.484 & 0.496 & 0.458 & 0.494 \\
\hline
\end{tabular}

The values in brackets report p-value significance levels.

$*, * *, * * *$ indicate significance at $10 \%, 5 \%$, and $1 \%$ levels, respectively.

Co-sourcing fees $(\mathrm{ln})$ is the natural logarithm of co-sourcing fees paid to support IA. Audit plan is a dichotomous variable that takes the value of 1 if the percentage of consulting-related activities in the 2015 audit plan is greater than (or equal to) 50 percent, and 0 otherwise. Risk areas is a dichotomous variable that takes the value of 1 if employees believe that IAF provides advice consulting on risk management activities, and 0 otherwise. IAF focus is the sum of Audit plan and Risk areas. Education is a dummy variable that takes the value of 1 if the employee holds a Master or a Doctorate degree, and 0 otherwise. Certification is a dichotomous variable that takes the value of 1 if the employee has a professional qualification or certification in internal audit, and 0 otherwise. Tenure is a dichotomous variable that takes the value of 1 if the number of years internal audit has taken place is greater than (or equal to) the median of the years, computed by geographic region, and 0 otherwise. Internal is a dichotomous variable that takes the value of 1 if internal audit activities are developed inside the organization, and 0 otherwise. Rotation is a dichotomous variable that takes the value of 1 if IAF employees rotate though other parts of the organization, and 0 otherwise. IAF expertise is divided into external and internal expertise. External expertise is the sum of Education and Certification, while internal expertise is the sum of Tenure, Internal, and Rotation. Source is a dichotomous variable that takes the value of 1 if the number of sources used to establish an audit plan is greater than 5 , and 0 otherwise. Modify is a dichotomous variable that takes the value of 1 if respondents never experienced a pressure to suppress or significantly modify a valid internal audit finding or report, and 0 otherwise. IAF autonomy is the sum of Source and Modify. Audit committee is a composite measure for audit committee existence and characteristics. Number of employees is the number of IAF employees. Total assets $(l n)$ is the natural logarithm of total assets. Sales $(l n)$ is the natural logarithm of sales. 